(79,9\%)[6], cao hơn rất nhiêu so với nghiên cứu của chúng tôi.

Thể tích khối máu tụ là một đại lượng mà Ridwan và cộng sự [5] sử dụng trong đánh giá máu tụ dưới màng cứng trước mổ để so sánh và tiên lượng kết cục điêuu trị và nguy cơ tái phát. Tuy nhiên, do đặc thù ở nước ta, bệnh nhân có thể được chup phim ở các cơ sở khác, đến khám và điều trị tại bệnh viện Việt Đức nên chúng tôi không chụp lại phim kiểm tra (khi đã đủ để chẩn đoán), nền không thể tính được thể tích khối máu tụ.

\section{KẾT LUÂ̂N}

Qua nghiên cứu hôi cứu 91 trường hợp máu tụ dưới màng cứng mạn tính, chúng tôi thấy tuổi trung bình trong nhóm nghiên cứu là 60 tuổi; tỉ lệ nữ chiếm khoảng 20\%. Hâu hết máu tụ dưới màng cứng mạn tính là do nguyên nhân chấn thương (72,53\%); tỉ lệ dùng thuốc chống đông/ngưng tập tiểu câu là 4,40\%. 87,91\% số bệnh nhân có điểm GCS $\geq 13$. Không có sự khác biệt về bên của khối máu tụ. Độ dày trung bình của khối máu tụ là 18,27士0,668 (mm).

\section{TÀI LIẸU THAM KHẢO}

1. Liu, W., N.A. Bakker, and R.J. Groen, Chronic subdural hematoma: a systematic review and meta-analysis of surgical procedures. J Neurosurg, 2014. 121(3): p. 665-73.

2. Mehta, V., et al., Evidence based diagnosis and management of chronic subdural hematoma: A review of the literature. J Clin Neurosci, 2018. 50: p. 7-15.

3. Kitya, D., et al., Causes, clinical presentation, management, and outcomes of chronic subdural hematoma at Mbarara Regional Referral Hospital. Neurosurg Focus, 2018. 45(4): p. E7.

4. Motiei-Langroudi, R., et al., Factors influencing the presence of hemiparesis in chronic subdural hematoma. J Neurosurg, 2019. 131(6): p. 1926-1930.

5. Ridwan, S., et al., Surgical Treatment of Chronic Subdural Hematoma: Predicting Recurrence and Cure. World Neurosurg, 2019. 128: p. e1010-e1023.

6. Kwon, C.S., et al., Predicting Prognosis of Patients with Chronic Subdural Hematoma: A New Scoring System. World Neurosurg, 2018. 109: p. e707-e714

7. Bartek, J., Jr., et al., Predictors of Recurrence and Complications After Chronic Subdura Hematoma Surgery: A Population-Based Study. World Neurosurg, 2017. 106: p. 609-614.

8. Tugcu, B., et al., Can recurrence of chronic subdural hematoma be predicted? A retrospective analysis of 292 cases. J Neurol Surg A Cent Eur Neurosurg, 2014. 75(1): p. 37-41.

9. Amirjamshidi, A., et al., Outcomes and recurrence rates in chronic subdural haematoma. $\mathrm{Br}$ ] Neurosurg, 2007. 21(3): p. 272-5.

\title{
SẸO THÂ̂N VÀ LIÊN QUAN ĐẾN CHỨC NĂNG BÀNG QUANG Ở BÊ̂NH NHÂN SAU MỔ DỊ TÂTT NỨT ĐỐT SỐNG BẨM SINH
}

\author{
Nguyễn Duy Việt ${ }^{1}$, Lê Anh Dũng ${ }^{1}$, Đỗ Mạh Hùng ${ }^{1}$, \\ Vũ xuân Hoàn ${ }^{1}$, Nguyễn Thanh Liêm ${ }^{2}$
}

\section{TÓM TẮT}

Mục đích: mô tả tổn thương thận và liên quan đến chưư năng bàng quang ở bệnh nhần sau mổ dị tật cột sống bẩm sinh. Đối tượng và phương pháp nghiên cứu: hồi cứu 62 bệnh nhân sau mổ dị tật nứt đốt sống bẩm sinh tại Bệnh viện nhi Trung ương từ $01 / 2013$ đến 31/03/2019. Tất cả bệnh nhân được chụp xạ hình thận mổ tả tổn thương sẹo thận và đo áp lực bàng quang với các chỉ số như giảm đổ co giãn bàng quang, thể tích bàng quang so với tuối $<65 \%$ và áp lực bàng quang $\geq 30 \mathrm{cmH}_{2} \mathrm{O}, \mathrm{p}<0,05$ có ý nghĩa thống kê. Kết quả: có 62 bệnh nhân sau mổ dị tật nứt đốt sống bẩm sinh trong đó thoát vị tủy màng tủy chiếm $72,6 \%$ và thoát vị mõ tủy màng tủy chiếm

${ }^{1}$ Bệnh viện Nhi Trung ương

2Bềnh viền Đa khoa Quốc tế Vinmec

Chịu trách nhiệm chính: Nguyễn Duy Việt

Email: bsnguyenduyviet@gmail.com

Ngày nhận bài: 4.01.2021

Ngày phản biên khoa học: 25.2.2021

Ngày duyệt bài: 10.3.2021
$27,4 \%$. Giới nam là $43,5 \%$ và $53,6 \%$ là giới nữ. Có 18 bệnh nhân sẹo thận chiếm 29,0\% sẹo thận, tuổi trung bình ở nhóm tổn thương thân cao hởn nhóm không có tổn thương thận: $5,1 \pm 3,1$ so với 2,4 $\pm 2,2$ tuổi với $p$ $=0,001$. Kết quả đo áp lực bàng quang với $41,9 \%$ bệnh nhân giảm độ co giãn bàng quang, 12,9\% trường hớp thể tích bàng quang so với tuổi $<65 \%$ và $22,6 \%$ bệnh nhân có áp lực bàng quang $\geq 30 \mathrm{cmH}_{2} \mathrm{O}$. Với những trường hợp giảm độ co giãn bàng quang có $61,5 \%$ sẹo thận, thể tích bàng quang so tuổi $<65 \%$ có $75,0 \%$ sẹo thân và áp lực bàng quang $\geq 30 \mathrm{cmH}_{2} \mathrm{O}$ có $71,4 \%$ sẹo thận, có ý nghĩa thống kê. Kết luận: seo thân liển quan đến chức năng bàng quang với giảm độ co giãn bàng quang, thể tích bàng quang so với tuổi $<65 \%$ và áp lực bàng quang $\geq 30 \mathrm{cmH}_{2} \mathrm{O}$ ở bệnh nhân sau mổ dị tật nứt đốt sống bẩm sinh.

Tư khóa: sẹo thận, dị tật nứt đốt sống bẩm sinh, đo áp lực bàng quang

\section{SUMMARY \\ RENAL SCARING AND RELATION TO BLADDER FUNCTION IN PATIENTS POST- OPERATIVE SPINAL BIFIDA}


Purpose: to discrible damage kidney and relation to bladder function in patients post-operative spinal bifida. Materials and Methods: Retrospectively reviewed the records of 62 patients in postoperative spinal bifida patients from 01.2013 to 31.03 .2019 at Nattional Hospital of Peadiatrics. All patients were done renal scintygraphy to show renal scars and cystometry with parameters include bladder compliance, bladder capacity compare to age $<65 \%$, bladder pressure $\geq 30 \mathrm{cmH}_{2} 0, p<0,05$ statistical significantly. Results: 62 patients in post-operative spinal bifida include myelomeningocele $72,6 \%$ and limpomyelomeningocele 27,4\%. Male was $43,5 \%$, female was $53,6 \% .18$ patients showed renal scars with $29,0 \%$, mean age in renal scars group were higher than non renal scars: 5,1 $\pm 3,1$ years compare to $2,4 \pm 2,2$ years, $p=0,001$. Cystometry results showed $41,9 \%$ patients with low bladder compliance, $12,9 \%$ cases with bladder capacity for age $<65 \%$ and $22,6 \%$ patients with bladder pressure $\geq 30 \mathrm{cmH}_{2} \mathrm{O}$. Patients with low compliance had $61,5 \%$ renal scars, patients with bladder capacity for age < 65\% had $75,0 \%$ renal scars and patients with bladder pressure $\geq 30 \mathrm{cmH}_{2} \mathrm{O}$ had $71,4 \%$ renal scars, statistical significantly. Conclusion: Renal scaring related to bladder function with low compliance, bladder capacity for age $<65 \%$ and bladder pressure $\geq 30$ $\mathrm{CmH}_{2} \mathrm{O}$, sitasitistic significantly patients in postoperative spinal bifida.

Key words: renal scar, spinal bifida, cystometry

\section{I. ĐẶT VẤN ĐỀ}

Bàng quang thần kinh (BQTK) hay rối loạn chức năng bàng quang thần kinh là hiện tượng rối loạn chức năng của hệ tiết niệu dưới do tổn thương hoăc bênh lý thần kinh [1]. Dị tật cột sống nứt đốt sống (DTNĐS) bẩm sinh là nguyên nhân thường gặp gây BQTK ở trẻ em, dị tật này liên quan đến thiếu hụt chất axit folic ở thời kỳ mang thai, tỷ lệ DTNĐS bẩm sinh khoảng 0.34.5/1000 trẻ sơ sinh sống trên thế giới, trong đó thoát vị tủy màng tủy chiếm đa số khoảng $95 \%$ [2]. Trào ngược bàng quang - niệu quản, nhiễm khuẩn tiết niệu tái diến dẩn tới viêm thận bề thận và hình thành sẹo thận ở DTNĐS bẩm sinh. Rối loạn chức năng bàng quang thần kinh ở bệnh nhân DTNĐS bẩm sinh là yếu tố nguy cơ gẩy tổn thương sẹo thận, như giảm độ co giãn bàng quang (CGBQ), áp lực bàng quang cao (ALBQ) và thể tích bàng quang (TTBQ) so với tuổi nhỏ. Chính vì vậy chúng tôi thực hiện đề tài "mô tả sẹo thận và liên quan đền chức năng bàng quang ở bệnh nhân sau mổ dị tật cột sông bầm sinh".

\section{II. ĐỐI TƯợNG VÀ PHƯƠ'NG PHÁP NGHIÊN CỨU}

Hồi cứu 62 bệnh nhân sau mổ dị tật nứt đốt sống bẩm sinh tại Bệnh viện nhi Trung ương, từ 01/2013 đến 31/03/2019. Tất cả bệnh nhân được chụp xạ hình thận mổ tả tổn thương sẹo thận và đo áp lực bàng quang với các chỉ số như giảm độ co giãn bàng quang, thể tích bàng quang so với tuổi $<65 \%$ và áp lực bàng quang $\geq 30 \mathrm{cmH}_{2} \mathrm{O}$. Số liệu được trình bày dưới dang bảng, hình và phân tích bằng phần mềm thống kê y học SPSS, $p<0,05$ có ý nghĩa thống kê.

\section{KẾT QUẢ NGHIÊN CỨU}

Có 62 bệnh nhân được đo ALBQ sau mổ DTNĐS bẩm sinh vùng thắt lưng cùng cutt, trong đó giới nam chiếm 43,5\% và 53,6\% trường hợp là trẻ nữ. Thoát vị tủy màng tủy chiếm đa số $72,6 \%$ và $27,4 \%$ trường hợp thoát vị mõ tủy màng tủy. Có 18 bệnh nhân tổn thương seo thân trên xạ hình thận chiếm $29,0 \%$. Đa số là tổn thương 2 bên thận chiếm 21,0\% (hình 1).

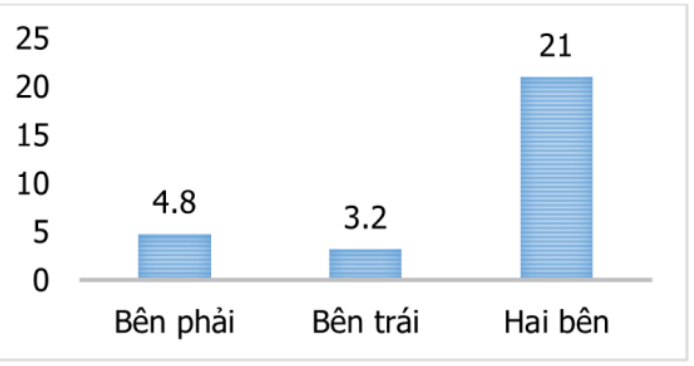

Hình 1. Tổn thương sẹo thận trên xạ hình

Tuổi trung bình của nhóm tổn thương thận là $5,1 \pm 3,1$ tuổi lớn hơn nhóm không tổn thương thận là $2,4 \pm 2,2$ tuổi, khác biệt có ý nghĩa thống kê với $p=0,001$.

Bảng 1. Kêt quả đo áp lực bàng quang

\begin{tabular}{|c|c|c|c|}
\hline \multicolumn{2}{|c|}{ CNBQ } & n & Tỳ lệ (\%) \\
\hline Đồ & Bình thường & 36 & 58,1 \\
\cline { 2 - 4 } CGBQ & Giảm & $\mathbf{2 6}$ & $\mathbf{4 1 , 9}$ \\
\hline \multirow{2}{*}{ ALBQ } & $<30 \mathrm{cmH}_{2} \mathrm{O}$ & 48 & 77,4 \\
\cline { 2 - 4 } & $\geq \mathbf{3 0} \mathbf{~ c m H}_{\mathbf{2}} \mathbf{O}$ & $\mathbf{1 4}$ & $\mathbf{2 2 , 6}$ \\
\hline \multirow{2}{*}{ TTQ } & $\geq 65 \%$ & 54 & 87,1 \\
\cline { 2 - 4 } & $<\mathbf{6 5 \%}$ & $\mathbf{8}$ & $\mathbf{1 2 , 9}$ \\
\hline
\end{tabular}

Nhận xét: có 8 bệnh nhân chiếm 12,9\% TTBQ nhỏ, 26 bênh nhẩn chiếm $41,9 \%$ giảm độ CGBQ và 14 bệnh nhân chiếm $22,6 \%$ có $A L B Q \geq$ $30 \mathrm{cmH}_{2} \mathrm{O}$.

Bảng 2. Liên quan chức năng bàng quang với tổn thương thận

\begin{tabular}{|c|c|c|c|c|}
\hline CNBQ & $\begin{array}{c}\text { Xạ hình thận } \\
\text { Sẹôn } \\
\text { thận }\end{array}$ & $\begin{array}{c}\text { Khồng } \\
\text { seoo thận }\end{array}$ & n & p \\
\hline $\begin{array}{c}\text { Giảm độ } \\
\text { CGBQ }\end{array}$ & $61,5 \%$ & $38,5 \%$ & 26 & 0,001 \\
\hline $\begin{array}{c}\text { TBQ }< \\
65 \%\end{array}$ & $75,0 \%$ & $25,0 \%$ & 8 & 0,006 \\
\hline $\begin{array}{c}\mathrm{ALBQ} \geq \\
30 \\
\mathrm{CmH}_{2} \mathrm{O}\end{array}$ & $71,4 \%$ & $28,6 \%$ & 14 & 0,001 \\
\hline
\end{tabular}


Nhận xét: giảm độ CGBQ, TTBQ so với tuổi $<65 \%$, ALBQ $\geq 30 \mathrm{cmH}_{2} \mathrm{O}$ liên quan đến tổn thương sẹo thẩn có ý nghĩa thống kê.

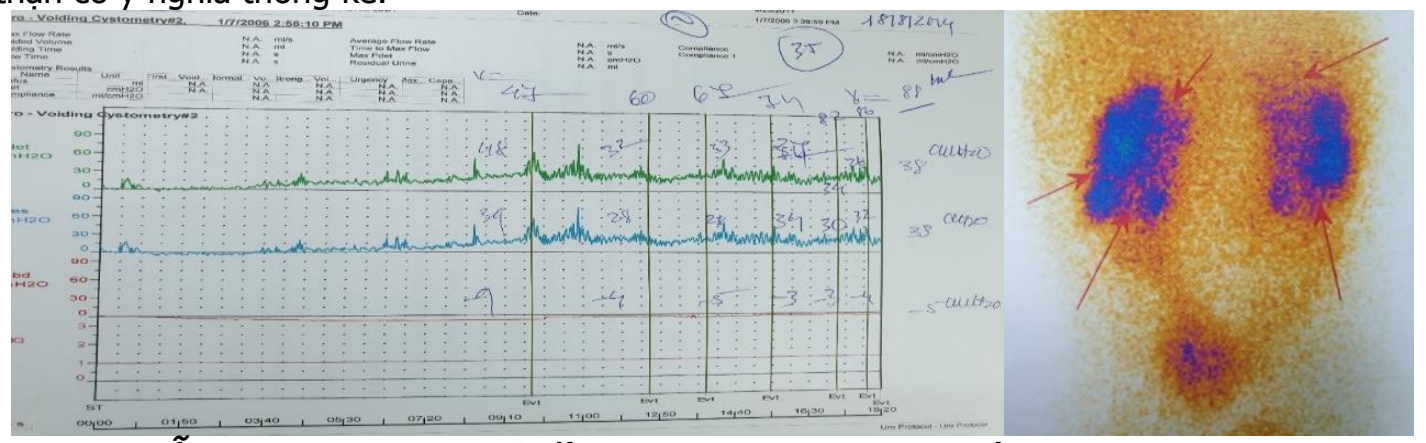

Hình 2. Nguyễn Thị Phương L, mã hồ sơ, 110256403, sẹo thận, $A L B Q>40 \mathrm{cmH}_{2} \mathrm{O} \mathrm{cmH} \mathrm{H}_{2} \mathrm{O}$, giảm độ CGBQ, TTBQ < 65\%

\section{BÀN LUẬN}

Khi so sánh với kết quả của một số tác giả thây tỷ lệ tổn thượng sẹo thận trong nghiên cứu của chúng tôi cao hơn và tuổi xuất hiện tổn thương thận sớm hơn (bảng 4.7). Có thể bệnh nhân trong nghiên cứu của chúng tôi được hướng dẫn CIC muộn và tỷ lệ dùng thuốc kháng giao cảm thấp, việc chỉ định dùng thuốc cũng khó khăn do không có nhiều loại để lựa chọn phù hợp theo tuổi, dẫn tới thay đổi CNBQ sẽ làm tăng nguy cơ tổn thương thận.

\section{Bảng 3. Tỷ lê tổn thường seo thân}

\begin{tabular}{|c|c|c|c|}
\hline Tác giả & $\begin{array}{c}\text { Số bềnh } \\
\text { nhẩn }\end{array}$ & $\begin{array}{c}\text { Tỷ lệ } \\
\text { (\%) }\end{array}$ & $\begin{array}{c}\text { Tuối } \\
\text { (năm) }\end{array}$ \\
\hline Dik và cs [3] & 144 & 4,2 & 6,8 \\
\hline Ozel và cs [4] & 312 & 23,1 & 6,5 \\
\hline Shiroyanagi và cs [5]. & 64 & 25,0 & 15,8 \\
\hline Chúng tôi & $\mathbf{6 2}$ & $\mathbf{2 9 , 0}$ & $\mathbf{5 , 1}$ \\
\hline
\end{tabular}

- Áp lực bàng quang: kết quả nghiên cứu của chúng tôi có $22,6 \%$ bệnh nhân có $A L B Q \geq 30$ $\mathrm{cmH}_{2} \mathrm{O}$, nhóm này có $71,4 \%$ trường hợp sẹo thận (bảng 1). Arora và cs (2006) khi phân tích một số yếu tố liên quan đến tổn thương sẹo thận ở bệnh nhân DTNĐS bẩm sinh thây ALBQ > 25 $\mathrm{cmH}_{2} \mathrm{O}$ là $8 / 9(88,9 \%)$ bệnh nhân có tổn thương sẹo thận so với nhóm khổng sẹo thận, $p<0,005$ [6]. Một nghiên cứu khác của tác giả Prakash và cS (2017) khi phân tích yếu tố tổn thương thận ở bệnh nhân BQTK, kết quả có 12,4\% trường hợp có tổn thương sẹo thận, ở nhóm này có $75 \%$ trường hợp có $A L B Q>40 \mathrm{cmH}_{2} \mathrm{O}$ với $\mathrm{p}=0,038$ [7]. Điêu này có thể giải thích là ở nhóm có ALBQ cao là yếu tố gây trào ngược bàng quangniêu quản, viêm thận bể thận và hậu quả lâu dài dẫn đến tổn thương seo thận.

- TTBQ so với tuổi: kết quả nghiên cứu của chúng tôi ở nhóm có TTBQ so với tuổi $<65 \%$, nhóm này có $75 \%$ trường hợp có sẹo thận, với $p=0,006$ (bảng 1). Kết quả của chúng tôi tương tự như kết quả của tác giả Bruschini và cs (2006) khi nghiên cứu 104 bệnh nhân thoát vị tủy màng tủy có $25,9 \%$ bệnh nhân có tổn thượng sẹo thận và có TTBQ so tuổi $<67 \%, p=$ 0,01 [8]. Arora và CS (2006) phân tích yếu tố nguy cơ tổn thương thân ở bệnh nhân thoát vị tủy màng tủy. Nhóm tổn thươning thận có TTBQ so với tuổi $<60 \%$, khác biệt so với nhóm không có tổn thương thận, với $p<0,005$ [6]. Ozel và cs (2006) khi đánh giá một số yếu tố ảnh hưởng đến tổn thương sẹo thận ở bệnh nhân BQTK do DTNĐS bẩm sinh thây trong nhóm sẹo thận có TTBQ so với tuổi $<69,6 \%$, so với nhóm không tổn thương thận, có ý nghĩa thống kê [4]. Như vậy, kết quả nghiên cứu của chúng tôi cũng như kết quả nghiên cứu của một số tác giả trên cho thấy TTBQ so với tuổi (TTBQ so tuổi < 67\%) ở nhóm tổn thương thận nhỏ hơn so với nhóm không có tổn thương thận. Điều này có thể giải thích khi mà TTBQ nhỏ sẽ làm cho ALBQ cao, từ đó tăng nguy có trào ngược BQ-NQ, giãn BT-NQ và viêm thận bể thận dẩn tới tổn thương thận.

- Giảm độ co giãn bàng quang: nhóm giảm độ CGBQ trong nghiên cứu của chúng tôi có $61,5 \%$ trường hợp có tổn thương sẹo thận, $p=0,001$ (bảng 1). Kết quả tương tự với kết quả nghiên cứu của các tác giả như Bruschini và cs (2006) đánh giá kết quả 104 bệnh nhân thoát vị tủy màng tủy có $25,9 \%$ bệnh nhân có tổn thương sẹo thận, nhóm sẹo thận có $51,9 \%$ bệnh nhân có giảm độ CGBQ, có ý nghĩa thống kê [8]. Ozel và CS (2006) khi phân tích một số yếu tố ảnh hưởng đến tổn thương sẹo thận ở bệnh nhân BQTK do DTNĐS bẩm sinh kết quả thấy trong nhóm seo thân có đến $80,6 \%$ bênh nhân giảm độ CGBQ, có ý nghĩa thống kê [4]. Như vậy, kết quả của chúng tôi cũng tương tự như kểt quả của một số tác giả trên chỉ ra giảm độ 
CGBQ liên quan đến tổn thương thận. Điều này có thể giải thích khi mà giảm độ CGBQ sẽ dẫn tới thay đổi $A L B Q$ cao là yếu tố nguy cơ gây tổn thương thận.

\section{KẾT LUẬN}

Sẹo thận liên quan đến chức năng bàng quang với giảm độ co giãn bàng quang, thể tích bàng quang so với tuổi $<65 \%$ và áp lực bàng quang $\geq 30 \mathrm{cmH}_{2} \mathrm{O}$, ở bệnh nhân sau mổ dị tật nứt đốt sống bẩm sinh.

TÀI LIÊU THAM KHẢO

1. Ginsberg D (2013). The Epidemiology and Pathophysiology. Am J Manag Care, 19, 191-196.

2. Bauer S.B (2008). Neurogenic bladder: etiology and assessment. Pediatr Nephrol, 23(4), 541-51.

3. Dik P, Klijn A.J, Van Gool J.D et al (2006). Early start to therapy preserves kidney function in spina bifida patients. Eur Urol, 49(5), 908-13.

4. Ozel S.K, Dokumcu Z, Akyildiz $C$ et al ( 2007). Factors affecting renal scar development in children with spina bifida. Urol Int, 79(2), 133-6.

5. Shiroyanagi Y, Suzuki M, Matsuno D et al ( 2009). The significance of 99mtechnetium dimercapto-succinic acid renal scan in children with spina bifida during long-term followup. J Urol, 181(5), 2262-6; discussion 2266.

6. Arora G, Narasimhan K.L, Saxena A.K et al (2006). Risk Factors for Renal Injury in Patients with Meningomyelocele. Indian Pediatrics, 44, 417-420.

7. Prakash $R$, Puri A, Anand $R$ et al (2017). Predictors of upper tract damage in pediatric neurogenic bladder. J Pediatr Urol, 13(5), 503 e1-503 e7.

8. Bruschini $H$, Almeida F.G, Srougi $M$ et al (2006). Upper and lower urinary tract evaluation of 104 patients with myelomeningocele without adequate urological management. World J Urol, 24(2), 224-8.

\section{KẾT QUẢ PHẪU THUÂ̂T KHÂU KÍN ỐNG MÂ̂T CHỦ SAU KHI LẤY SỎI ĐỂ ĐIỀU TRİ SỎI ĐƯờNG MÂTT CHÍNH NGOÀI GAN TĂI BỆNH VIỆN BẠCH MAI}

\section{TÓM TẮT}

Mục tiêu: Kết quả của phương pháp khâu kín ông mật chủ sau khi lấy sỏi để điều trị sỏi đường mật chính ngoài gan. Đối tượng và phương pháp nghiên cứu: Mô tả hồi cứu 70 bệnh nhân được phẫu thuật mở bụng, mở ống mật chủ lấy sỏi và khẩu kín OMC ngay tại Khoa Ngoại Bệnh viện Bach Mai từ 2014 đến 2020. Kết quả: 70 trường hợp trong nghiên cứu bao gồm 42 nữ và 28 nam, tuổi trung bình là 62 $\pm 15,2$ tuổi, 34 trường hợp $(48,5 \%)$ có tiền sử mổ sỏi mật, thời gian nằm viện sau mổ là $7,91 \pm 2,07$ ngày, không có tử vong sau mổ, tỉ lệ biến chứng chung là $10,0 \%$ trong đó tụ dịch dưới gan là chủ yếu $5,7 \%$, Kết luận: phẫu thuật khâu kín ống mật chủ sau khi lấy sỏi an toàn, hiệu quả. Chỉ định cho các trường hợp lấy hết sỏi ống mật chủ, không có sỏi trong gan, cơ Oddi thông tốt, dịch mật trong sạch.

Tư khóa: Sỏi ống mật chủ; khâu kín ống mật chủ

\section{SUMMARY}

PRIMARY CLOSUSE COMMON BILE DUCT AFTER REMOVER STONE AT BACH MAI HOSPITAL

Aims: Objective: The results of primary closure after remover stones for the treatment of common bile duct (CBD) stone. Matarial and Methods: A

*Bệnh viện Bạch Mai

Chịu trách nhiệm chính: Trần Mạnh Hùng

Email: tranmanhhungngoaibm@gmail.com

Ngày nhận bài: 2.01.2021

Ngày phản biên khoa học: 25.2.2021

Ngày duyệt bài: 10.3.2021 retrospective study of 70 patients with open abdominal surgery, common bile duct exploration for removal stones and primry closure CBD at Bach Mai Hospital from 2014 to 2020. Results: 70 cases in the study included 42 females and 28 males, mean age 62 \pm 15.2 years, 34 cases $(48.5 \%)$ had CBD stones recurent, postoperative hospital stay was $7.91 \pm 2.07$ days, there was no postoperative mortality, complication rate was $10.0 \%$, in which the hepatic fluid was $5.7 \%$. Conclusion: Primary closure common bile duct after removal stones is safe and effective

Key word: primary closure common bile duct; common bile duct stone

\section{I. ĐĂT VẤN ĐỀ}

Phẫu thuật mở bụng, mở ống mật chủ (OMC) lấy sỏi vẫn là phương pháp chủ yểu trong điêu trị sỏi đường mật chính với các trường hợp có chống chỉ định hoặc không thực hiện được bằng phẫu thuật nội soi (PTNS). Khi mở ống mật chủ lấy sỏi, dẫn lưu Kehr được sử dụng. Mục đích của dẫn lưu Kehr là giảm áp đường mật, dẫn lưu dịch mật nhiếm trùng, tạo ra đường vào để lấy sỏi còn sót lại. Khi các vấn đề trên được giải quyết thì không nhất thiết phải đặt ống dẫn lưu Kehr. Tại khoa Ngoại Bệnh viện Bạch Mai chúng tôi đã tiến hành khâu kín ống mất chủ sau khi lấy sỏi để điêu trị sỏi đường mật chính ngoài gan trong phẫu thuật mở cho nhiều trường hợp đạt kết quả tốt. Nghiên cứu này nhằm mực tiêu: Đánh giá kêt quả của phương pháp phẫu thuật 